\title{
Stretching SIEM
}

\section{Using Picturebooks to Connect STEM and literacy}

\author{
MARYYKATE SABLESKI
}

$\mathrm{S}$ TEM is an integral component to today's library programming, engaging children in active, hands-on experiences and building interest in these critical fields. There is a documented dearth of representation across women and minorities in STEM fields, and programming in public libraries can help to close this gap by fostering an early interest in science, technology, engineering, and math in all children, regardless of their background or access to STEM curriculum in school.

Librarians are uniquely poised to develop programs that not only engage students in STEM topics, but also help them develop literacy skills. Librarians are well aware of the need for children to be exposed to books early and often as they grow into independent readers. By bringing together the development of essential literacy skills through read-alouds, vocabulary enrichment, and rich discussion, as well as the exploration of STEM topics through hands-on, immersive experiences, we can capitalize on the varied interests and skills children bring to our storytimes and other programs.

Connecting STEM and literacy through purposeful, meaningful book selection and program planning can help children consider the possibilities of topics they may not naturally gravitate toward, opening up doors and opportunities they may not have otherwise considered.

Purposeful book selection to connect STEM and literacy learning goes beyond simply selecting books to complement a topic, such as reading a book about building design when discussing architecture. Rather, book selection to meaningfully connect STEM and literacy learning involves consideration of the STEM connections, as well as the literary quality and opportunities for vocabulary or comprehension development inherent in the book.

Further, book selection for STEM/literacy connections should consider the "windows and mirrors," images that both reflect and widen the perspectives of all children. Addressing the underrepresentation of diverse groups in STEM fields requires that children begin to see themselves and others in STEM professions, a function diverse literature can serve. Meaningfully connecting STEM and literacy learning through purposeful book selection and intentional program design will provide these windows and mirrors for children to see the diverse potential in these fields. From there, children can open the "sliding glass door" to engage and envision a future in the rapidly growing STEM professions. ${ }^{2}$

The books described in this article are examples that not only stimulate discussion about STEM topics, but also provide ample opportunities for the development of critical literacy skills. These books, utilized as part of a STEM/literacy afterschool enrichment program for struggling readers, were selected to ignite interest in the topics, while also engaging children in complex vocabulary and story structures.

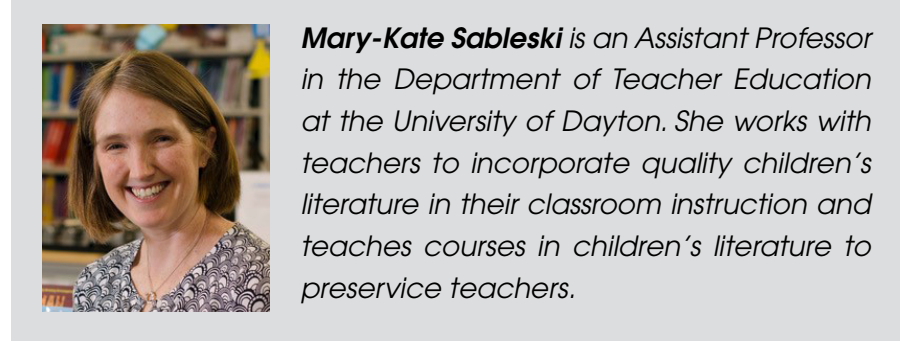


Williams, Karen Lynn. Galimoto. Illus. by Catherine Stock. HarperCollins, 1990. 32p.

Kondi is an African child determined to make a "galimoto," a toy vehicle made of wires. Although his brother laughs at the idea, Kondi spends all day gathering wires. By the end of the day, his galimoto is ready to be played with by all of the children in the village. As an example of global literature, this book provides a perspective on the universal experiences of childhood across cultures.

By reading about Kondi's galimoto, children can become inspired to build their own toy using recycled materials. Children can make personal connections to the story and connect their background knowledge to the new understandings about Kondi's culture they gain from reading the story. STEM connections include the engineering design process, mathematical problem solving, and hypothesis testing. Through collaboration and persistence, students can experience the design process from start to finish with an authentic purpose.

Rusch, Elizabeth. Volcano Rising. Illus. by Susan Swan. Charlesbridge, 2013. 32p.

This nonfiction book highlights volcanoes through vibrant photography and lyrical language. It describes what happens when a volcano erupts and depicts some historical eruptions.

Children can discuss what they expect to learn about volcanoes before reading the book, based on their prior knowledge. They can compare what their expectations were for the information presented to what they actually learned, helping them add new information to their previous understandings about volcanoes. Once they learn about volcanoes and eruption, students can work together to design a structure that would divert the flow of lava. They can also investigate the properties of lava and explore the geologic connections using supplementary texts and multimedia resources of volcanoes erupting.

Larson, Kirby, and Nethery, Mary. Two Bobbies: A True Story of Hurricane Katrina, Friendship, and Survival. Illus. by Jean Cassels. Bloomsbury, 2008. 32p.

Dog, Bobby, and Bob Cat are best friends living in New Orleans. The book follows the two animals' friendship and survival after Hurricane Katrina. Hurricane Katrina brought up issues of racial discrimination, and although these issues are not directly addressed in the story, it can act as an entry point into these critical conversations.

This is a rich story with multiple opportunities to connect literacy skills and STEM learning. The animal focus draws young readers in, hooking students into the issues created when hurricanes cause destruction. Children can create character maps of each of the animals, discussing the characteristics that enable them to help each other survive the

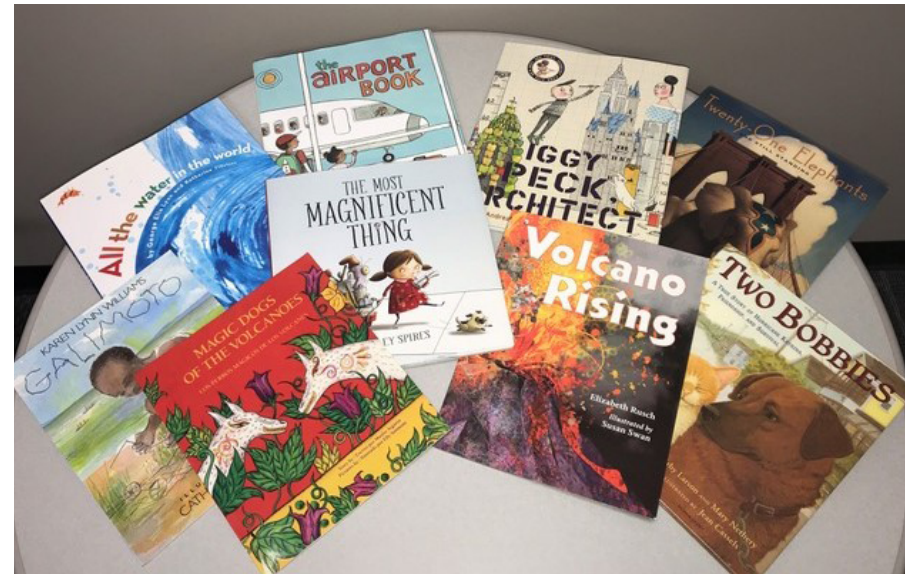

hurricane. STEM connections include the meteorological causes of hurricanes, designing structures to rescue stranded victims, and mathematical problem-solving related to time and distance of hurricane travel and effects.

Spires, Ashley. The Most Magnificent Thing. Illus. by the author. Kids Can Press, 2014. 32p.

The little girl in the book has a wonderful idea. With the help of her dog, she tries to make the most magnificent thing. While she knows exactly how it will work and how it will look, making the magnificent thing proves to be more difficult than she expected. After failing multiple times, the little girl decides to quit before eventually returning to the project and successfully making the magnificent thing.

Like Galimoto, this book offers opportunities for children to be creative and inventive. This book invites the literacy skills of sequencing and retelling, as the reader can trace a clear beginning, middle, and end to the story. STEM connections abound in this book as children are encouraged to develop their own magnificent things, using the engineering design process and collaborative thinking.

Lyon, George Ella. All the Water in the World. Illus. by Katherine Tillotson. Simon \& Schuster, 2011. 40p.

This book (poetry and nonfiction prose) provides facts about water while teaching about the water cycle and the need for water conservation. The illustrations and word placement complement the information about the water cycle, helping readers make connections.

Engaging children in poetry can involve multiple experiences, including having children read the book chorally, taking turns reading lines of the poem in a performance style, or illustrating specific powerful words from the poem. STEM connections can include a study of the water cycle and water filtration methods. Children can examine methods of water filtration and even try some out on their own using basic materials. Using the engineering design process as a base, children can make connections to water filtration systems around the world and consider how to bring them to places 
in need. Discussing places in the world that do not have easy access to clean water can also inspire conversations surrounding diversity and global issues.

Brown, Lisa. The Airport Book. Illus. by the author. Roaring Brook, 2016. 40p.

This book follows a family at the airport-checking their bags, going through security, and waiting at the gate. At the bottom of each page, the reader follows the young child's missing sock monkey as it makes its own journey through the airport. The book includes representation of diverse groups in the illustrations of the people at the airport.

The STEM connections in this book are fun to create because of the powerful "hook" created by the book. The book is engaging to young children, as they can trace the sock monkey's journey through the airport. Multiple storylines are happening in this book, with the monkey's journey occurring at the bottom of the pages, the family navigating the airport, and the background characters included on each page. Librarians can engage children in a multimodal reading of the text, in which they examine how the illustrations and the text work together to tell the story.

From a STEM perspective, children can consider the various components of an airport, including the conveyer belt, the security scanner, and the science of flight. Using the engineering design process, students can consider how to create a conveyer belt out of everyday materials to understand how this design works.

Beaty, Andrea. Iggy Peck, Architect. Illus. by David Roberts. Abrams, 2007. 32p.

Iggy Peck is a second grade student who loves to design and create. However, when his teacher declares her dislike of architecture, Iggy faces a challenge. Thankfully, a class field trip proves to everyone just how useful an architect is. The book includes limited representation of diversity, but does incorporate both female and male perspectives on a traditionally male-dominated field.

Iggy Peck is a compelling, relatable character. Children can ask questions as they read and learn about architecture, modeling and practicing the reading strategy of asking questions to monitor comprehension. Architecture provides numerous STEM connections. Children can explore the career of architecture, considering all of the skills involved in pursuing this career. They can also engage in making blueprints, drawing designs for buildings and structures of their creation.

Prince, April Jones. Twenty-One Elephants and Still Standing. Illus. by Francois Roca. Houghton Mifflin, 2005. 32p.

Once the Brooklyn Bridge, which connects Brooklyn and New York City, was completed, everyone wanted to know just how much it could hold. To prove how strong it was, Phineas T. Barnum paraded twenty-one elephants across the span.

This book is a good example of the historical fiction genre. The illustrations are rich and inviting, and students can use their multimodal skills in a complete reading. Children can draw themselves into the historical scene, considering the role they would have liked to have played in the building of the bridge to make connections to the story. This is an ideal book to explore bridge design using the engineering design process. Using building materials such as K'Nex, children can build bridges, then test them using weights. Children can also examine bridges around the world to study how they were designed.

Van Dusen, Chris. If I Built a House. Illus. by the author. Dial, 2012.32p.

Jack "builds" a house of his dreams that includes a racetrack, flying room, and a gigantic slide. Jack has limitless creativity and an imagination that allows him to design a house anyone would love.

With a wonderful entry into childlike imagination, this book will inspire children to see, build, and create. The endpapers invite an examination of blueprint design, and children can draw their own blueprints for their "house of dreams." Using everyday materials, children can build a house while learning how to balance their dreams with the realities of building design. Children can even see if their houses would withstand the elements, in a "three little pigs" style, using wind and water to test their structures.

Thompson, Laurie Ann. Emmanuel's Dream. Illus. by Sean Qualls. Schwartz \& Wade, 2015. 40p.

This book tells the story of Emmanuel Yeboah, a man born with a disability in a small village in Africa. Emmanuel dreams of biking across Africa with only his one strong leg. With great determination, he is able to do just that. The book shows that having a disability does not mean that a person is unable to reach their greatest dreams. In addition, this book connects with Galimoto by telling a global story of diversity.

With an authentic purpose built right into the story, this book allows children to consider the real-world problem of navigating an able-bodied world with a physical disability. Children can brainstorm tasks that would be challenging for people with limited mobility, then work together to design supports to address these challenges. For example, putting on a sock is challenging for those with limited arm function, so students can use everyday materials to design a grabber hook to help pull the sock on to the foot. The engineering design process takes center stage as children identify and work together to address real-world problems. 
Bailey, Linda. Stanley at Sea. Illus. by Bill Slavin. Kids Can Press, 2008. 32p.

This book tells the story of Stanley, a dog who is always hungry and whose owners always seem to be eating. One day, Stanley wanders down to the river where he meets canines Alice, Nutsy, and Gassy Jack. Soon their keen noses lead them to a delicious treat on a small boat with no people in sight. When the boat's mooring comes loose, the boat floats away with the dogs still on board! The book follows the dogs' adventure as they try to get back to land.

This engaging story brings children into the back door of a STEM challenge. Numerous examples of characterization, dialogue, and predictive opportunities occur throughout the story. For children who are reluctant or uncertain of engaging in STEM activities, this book can encourage and challenge. Using the engineering design process, they can design a rescue aid to reach Stanley and bring him safely home.

Hooks, Gwendolyn. Tiny Stitches. Illus. by Colin Bootman. Lee \& Low, 2016. 32p.

This book tells the story of Vivien Thomas, a young black man who dreamed of becoming a doctor. After losing his savings in the stock market crash of 1929, Vivien took a job at Vanderbilt University under Dr. Alfred Blalock. Vivien knew that the allwhite university would not admit him as a student, but he hoped working with the doctor would get him closer to his dream. Based on his research and experiments as Blalock's research assistant, Vivien developed a procedure that was used for the first successful open-heart surgery on a child. This book directly addresses issues of diversity in a historical context.

As a complex story based in a historical context, this book presents opportunities for story mapping and determining the central theme. Key vocabulary terms related to the medical field are also important to discuss throughout the story. The STEM connections in this book can relate to the tools used in surgery, in which students can develop a surgical instrument to be used in delicate surgeries. Students can explore related career connections in medicine, not limited to becoming surgeons, and consider the skills and experiences they would need to pursue these careers. Using the engineering design process, children can ponder building a tool for various surgical situations.

Holub, Joan. The Knights Before Christmas. Illus. by Scott Magoon. Holt, 2015. 32p.

This book, in poetry form, tells the story of three brave knights who were just settling in for the night on December 24 when out on the drawbridge, there arose such a clatter! The knights work together to try and get rid of the invader, Santa Claus, a "red-and white knight," and his eight dragons.

Predictive opportunities abound in the book as children consider what will happen at each stage. From a STEM perspective, children can explore the science of catapults, considering how to help Santa Claus get the presents into the castle. \&

\section{References}

1. Rudine Sims Bishop, "Mirrors, Windows, and Sliding Glass Doors,” Perspectives 6, no. 3 (1990): ix-xi.

2. Bishop, "Mirrors, Windows, and Sliding Glass Doors." 